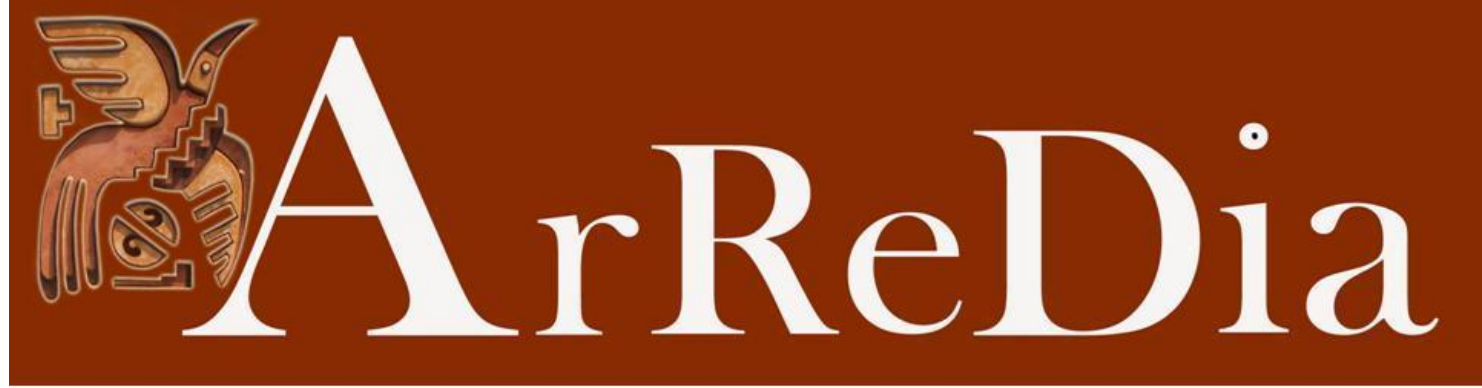

Revista da Faculdade de Comunicação, Artes e Letras / UFGD

\title{
NOTAS SOBRE OS PROCESSOS DE CONSTITUIÇÃO IDENTITÁRIA DE INDÍGENAS TERENAS NAS REDES SOCIAIS
}

\author{
Processes of identity constitution of terena indigenous in social networks
}

\author{
Nair Cristina Carlos de Medeiros ${ }^{i}$ \\ Universidade Federal da Grande Dourados \\ Claudete Cameschi de Souzaii \\ Universidade Federal do Mato Grosso do Sul
}

Resumo: O processo de diáspora vivido pelo povo Terena e o seu posterior reajuntamento afetaram o modo de vida e operaram grandes mudanças na paisagem ecológica e social desse povo indígena, o qual se viu, a partir daí, forçado a buscar novas estratégias de sobrevivência em um processo crescente de territorialização e de busca de autoafirmação nos territórios ocupados. Devido a este processo, há um discurso corrente de estigmatização dos povos Terena que assevera que eles abandonaram suas raízes, se aculturaram e se tornaram "índios urbanos". Neste contexto de estigmatização e de institucionalização de sentidos vários sobre o sujeito índio, nos propomos a problematizar as representações imaginárias desses sujeitos sobre si mesmos, através da publicação de uma postagem no Facebook realizada por um professor indígena destes povos. Nossa referência teórica é a Análise do Discurso de linha francesa a partir dos conceitos de memória, interdiscurso e formações discursivas propostos por Pêcheux (2009), da formulação do conceito de formações discursivas realizada por Foucault (1986) e da problematização de noções como identidade e processos identitários propostas por Hall (2006) e Coracini (2003), além das concepções de território e territorialidade e propostas por Haesbart (2004). Os resultados iniciais apontam para identidades construídas a partir das relações territoriais que encenam
Abstract: Diaspora lived by the Terena people and their subsequent gather affected the way of life and they underwent great changes in the ecological and social landscape of this indigenous people, which from then on, was forced to look for new strategies of survival in a process Territorialisation and the search for selfassertion in the occupied territories. Due to this process, there is a current discourse of stigmatization of the Terena people who assert that they have abandoned their roots, acculturated and become "urban Indians." In this context of stigmatization and institutionalization of various meanings on the Indian subject, we propose to problematize the imaginary representations of these subjects on themselves, through publications of postings on Facebook carried out by indigenous teachers of this ethnic group. Our theoretical reference is the French Discourse Analysis through the concepts of memory, interdiscourse and discursive formations proposed by Pecheux (2009), the formulation of the concept of discursive formations by Foucault (1986) and the problematization of notions such as Identity and identity processes carried out by Hall (1997) and Coracini (2003), , as well as the territorial and territorial conceptions proposed by Haesbart (2004). The initial results point to identities built from the territorial relations that stage the operation 
o funcionamento de diferentes posições sujeito, constituídas em duas formações discursivas que estão relacionadas entre si por oposição.

Palavras-chave: Processos identitários. Povos Terenas. Análise do discurso. of different subject positions, constituted in two discursive formations that are related to each other by opposition.

Keywords: Identity. Indigenous. Te Discourse Analysis.

\section{Introdução}

O processo de diáspora vivenciado pelo povo Terena e seu posterior reajuntamento afetaram o modo de vida e produziram grandes transformações nas práticas culturais desse povo, que se viu, desde então, forçado a buscar novas estratégias de sobrevivência em um processo crescente de (re)territorialização e de busca de autoafirmação nos territórios ocupados. Devido a este processo, há um discurso corrente de estigmatização dos Terenas que assevera que eles abandonaram suas raízes, se aculturaram, "deixaram de ser índios" ou se tornaram "índios urbanos". Neste contexto de estigmatização e de institucionalização de sentidos vários sobre o sujeito índio, propomo-nos a problematizar as representações imaginárias desses sujeitos sobre si, a partir de uma publicação na rede social Facebook. São territorialidades próprias que se configuram como importante elemento na constituição identitária desse povo, singularizando-os tanto no que refere à luta pelo direito à terra, quanto na relação com a cultura do "homem branco" em seu entorno.

Nossa referência teórica é a Análise do Discurso de linha francesa a partir dos recortes conceituais de memória, interdiscurso e formações discursivas propostos por Pêcheux (2009), da formulação do conceito de formações discursivas realizada por Foucault (1986) e da problematização de noções como identidade, processos identitários e fronteira realizadas por Hall (1997), Coracini (2003), além das concepções de território e territorialidade propostas por Haesbart (2004). 


\section{Referencial teórico}

Dado o complexo arcabouço teórico da Análise do discurso de linha francesa e os limites desse trabalho, focalizaremos apenas os conceitos que serão necessários para a análise que empreenderemos: memória, interdiscurso e formações discursivas. Em consonância com a perspectiva teórica assumida, consideramos que o sujeito é múltiplo, heterogêneo, clivado, "fragmentado, esfacelado, emergindo apenas pontualmente pela linguagem, lá onde se percebem lapsos, atos falhos" (CORACINI, 1995, p. 11). A linguagem, por sua vez, não é transparente, não é neutra; carregada de conteúdos simbólicos, através dela confrontamo-nos cotidianamente com o mundo, com os outros sujeitos, com os sentidos, com a história, contribuindo, com os nossos pensamentos e ações, para reproduzi-los ou transformá-los. A linguagem é efeito de sentidos entre sujeitos historicamente situados, articula conflitos e relações de poder, constitui subjetividades e identidades.

Se compreendermos as identidades como sendo formadas por fragmentos de crenças, valores, ideologias que nos precedem e que recebemos como herança - e que, por isto mesmo, podem sofrer modificações, transformações, - é possível afirmar que elas se constroem na/através da linguagem. Estes fragmentos de múltiplos fios dos discursos que constituem a memória discursiva se entrelaçam, se mesclam e se entretecem formando o interdiscurso (PECHÊUX, 2009).

Para Foucault (1987, p. 43), os discursos são uma dispersão, ou seja, são formados por elementos que não estão ligados por nenhum princípio de unidade a priori, cabendo à Análise do Discurso descrever essa dispersão, buscando as "regras de formação" que regem a formação dos discursos. Assim, para o autor, “sempre que se puder descrever, entre um certo número de enunciados, semelhante sistema de dispersão e se puder definir uma regularidade entre os objetos, os tipos de enunciação, os conceitos, as escolhas temáticas, teremos uma formação discursiva" formada por agrupamento de enunciados que adquirem estatuto de "atos discursivos sérios", isto é, enunciados que manifestam uma incessante "vontade de verdade". 
Através dessa rede discursiva, expressamos e simbolizamos nossa realidade cultural, criamos e incorporamos experiências e nos constituímos enquanto sujeitos sociais. Assim, não podemos falar em identidades fixas ou permanentes, as identidades são formadas e transformadas continuamente, tornando-se uma “celebração móvel” (Hall, 2006). Segundo Rajagopalan (1998), as identidades estão sempre em estado de fluxo, pois possuímos inúmeras matrizes identificatórias e somos portadores de várias identificações. As múltiplas vozes que são caracterizadas "pela dispersão, pela heterogeneidade, inteiramente vinculada ao momento histórico-social e ideológico, atravessam, de forma conflituosa e dissonante, a constituição identitária do sujeito" (CORACINI, 2003, p. 113). Se esse sujeito, como dissemos, é múltiplo, heterogêneo, clivado, barrado, não nos é possível falar de identidade como algo acabado, estável e fixo. Por isso, compreendemos que a identidade somente pode ser capturada por irrupções diversas no fio do discurso, quando o sujeito, inconscientemente, permite vir à tona a sua heterogeneidade.

Junto a este quadro teórico, utilizaremos os conceitos de território e territorialidade propostos por Haesbart (2004), uma vez que a trajetória de vida do povo Terena, suas lutas pela terra, suas constantes transformações e, por consequência, seus processos identitários, encontram-se em estreita relação com as suas territorialidades. Assim, a territorialidade aqui será abordada com o objetivo de compreender melhor a história da ocupação do território pelo povo Terena e as relações deste processo com as práticas culturais desse povo.

Partimos de uma concepção de território intrinsecamente articulada às relações de poder, poder compreendido aqui não apenas como o poder do estado, poder institucional, mas em termos relacionais, isto é, o poder que é inerente às relações sociais e que não é adquirido, mas simplesmente exercido. São essas relações de poder que, ao se apropriarem do espaço, formam os territórios e os caracterizam de acordo com suas práticas econômicas, políticas e culturais que "desdobra-se ao longo de um continuum que vai da dominação político-econômica mais 'concreta' e 'funcional' à apropriação mais subjetiva e/ou 'cultural-simbólica'” (HAESBART, 2004, p. 95-96). 
Se o território está relacionado à apropriação concreta e simbólica do espaço, à dominação e à posse, a territorialidade, por sua vez, é formada pelas relações sociais estabelecidas no território. A partir desta compreensão de territorialidade que articula as práticas culturais e econômicas de um povo em relação com o seu espaço, podemos perceber uma estreita relação entre a noção de territorialidade e os processos identitários. A territorialidade produz identidades à medida que sujeitos que compartilham e significam coletivamente o mesmo lugar desenvolvem o sentido de pertencimento àquele lugar e àquelas práticas, criando assim pontos de identificação uns com os outros que convivem dentro dos limites daquele território.

Assim, desta posição que busca analisar os discursos, pensamos ser possível problematizar os processos de identificação articulados aos processos de territorialização e os jogos discursivos que se instauram nesta articulação.

\section{A vivência territorial e os processos identitários Terena}

Com uma população estimada em 16.000 pessoas, os Terenas vivem atualmente em um território fragmentado e espalhado por sete municípios do Mato Grosso do Sul (MS):_Miranda, Aquidauana, Anastácio, Dois Irmãos do Buriti, Sidrolândia, Nioaque e Rochedo, mas sua maior concentração está nos municípios de Miranda (Área Cachoeirinha) e Aquidauana (Área Taunay/Ipegue). Os povos Terenas possuem presença marcante no cotidiano da vida sul mato-grossense, seja por sua participação nas relações de comércio informal pelas ruas das cidades onde residem, seja na realização de trabalho temporário informal nas fazendas da região. Estas práticas econômicas podem ser melhor compreendidas ao considerarmos que a história deste povo se confunde com a história de lutas e reinvindicações de seus territórios originais, trajetória marcada pela rejeição e pela negação da sociedade envolvente e que produz diferentes formações discursivas que ora os caracteriza como índios dóceis, ora como índios interesseiros, ora como índios urbanos ou não índios (VARGAS, 2011). 
Ao deixarem seus territórios tradicionais para lutarem junto ao Brasil na Guerra contra o Paraguai, os Terenas se viram diante de uma profunda dispersão de suas aldeias, uma vez que, findo o conflito, quando começaram a retornar aos seus territórios tradicionais, estes já haviam sido tomados em grande parte por terceiros. Os povos Terenas foram forçados, neste contexto, a buscar novos espaços e novas formas de exercício de sobrevivência. Dentre as estratégias adotadas, as mais comumente apontadas têm sido a abertura para o diálogo e a negociação, a facilidade de se abrir para o exterior, buscando incorporar ao seu patrimônio cultural, as experiências, práticas e memórias de outros povos (AZANHA, 2001). Segundo Azanha (2001), a partir da década de 80, o crescimento da população Terena, a exiguidade de área para a lavoura e a degradação de seu território afetaram diretamente a agricultura - principal atividade econômica exercida por esse povo até então - nas reservas Buriti, Cachoeirinha e Taunay-ipegue, fato que levou o autor a afirmar que não se vive da Reserva, mas na Reserva. Esta afirmação de Azanha interessa-nos especialmente para pensarmos a relação entre os processos de territorialização vivenciados pelo povo Terena e seus processos identitários.

É nesse contexto de institucionalização de sentidos vários sobre o sujeito índio que pretendemos entrever as relações entre os processos de ocupação dos territórios, as territorializações e as representações desses sujeitos sobre si mesmo. Assim, sempre considerando a trajetória e a relação com seus territórios, apresentamos a seguir as diferentes formações discursivas, os interdiscursos e os efeitos de sentido possíveis que perpassam a memória discursiva dos Terenas a partir da análise de uma sequência discursiva publicada no Facebook por um professor Terena: 


\section{$6 x^{2}$}

\section{1 de setembro $-\theta$}

Aquela forte temporal deixou muito estrago de muitas familias aqui na minha aldeia mais a minha CASA PALHA DE SAPE NAO TEVE NEM DANO ALGUMA ESSA TEPESTADE MAIS A OUTRA MINHA CASA DE TELHA AVOOU DE TODOS OS LADOS AINDA A MINHA FAMILIA CORREU RISCO DE SER ATINGIDO POR QUALQUER PEDAÇO DA TELHAS MAIS A MINHA CASA PALHA DE SAPE FIXA MAIS SEGURO E MUITO GOSTOSO DE MORAR O SEU AMBIENTE E MUITA FRESCA ENTAO MEU POVO TERENA POR ISSO QUE E MUITO BOM PARA NAO DEIXAMOS O MODO DE NOS E A MANEIRA DE NOS VIVERMOS ISSO EA MINHA PEQUENA REFLEXAO. NOS NAO TEMOS MOTIVO DE NOS DEIXARMOS A MANEIRA DE NOS VIVERMOS ISSO NOS APRENDEMOS COM OS NOSSO ENTES QUERIDOS OS NOSSOS MESTRES OS NOSSOS AVOS OS NOSSOS PATRONOS ISSO O QUE APRENDEMOS DELES NOS NAO TEMOS MOTIVOS NOS DEIXAMOS NOS TIMOS Q VIVER DESSA MANEIRA DEIa coisas dos purutuye de lado.

Compartilhar

B 5 pessoas curtiram isso.

Na sequência discursiva, temos uma postagem de um indígena que relata os estragos provocados por um temporal nas casas da aldeia em que vive ${ }^{1}$, buscando convencer o seu povo de que as casas de sapé são melhores que as casas de alvenaria. Podemos depreender neste trecho posições sujeito diferentes: há uma posição de identificação com a cultura do branco que advoga a modernidade e o progresso, representados pela casa de alvenaria e outra posição de identificação com a cultura dos índios, a cultura da tradição, representada pela casa de sapé e transmitida, segundo o enunciado, pelos antepassados. Lembra-nos a clássica história dos três porquinhos em que as casas são construídas com estruturas e materiais diferentes: palha, pau e tijolo. Na versão aceita como original, e amplamente divulgada para as crianças da cultura ocidental, os dois porquinhos

\footnotetext{
${ }^{1}$ Importante contextualizar que, nos últimos cinco anos, através de projetos e incentivos vários, os órgãos governamentais construíram casas populares de alvenaria em aldeias indígenas Terenas e de outros povos do MS. Em Aquidauana mais especificamente, muitos indígenas vivem nestas casas populares recebidas, mas, por dificuldades de adaptação, não desocuparam suas antigas casas de sapé, passando a viver em duas casas ao mesmo tempo.
} 
menores são devorados quando suas casas de palha e de madeira são destruídas e apenas o mais velho, cuja casa é feita de alvenaria, escapa devido à natureza da construção empregada, da sua capacidade de trabalho e de sua sabedoria. Há no interdiscurso a afirmação com grande valor de verdade de que as casas de tijolos são mais fortes e melhores.

No fragmento em análise, o emprego de marcas linguísticas indicadoras de contraposição - a partir do uso da conjunção adversativa mas (representada em sua forma coloquial "mais") expõe os dizeres oriundos de outras regiões de sentido e as filiações do sujeito com as formações discursivas com as quais se identifica. Assim, os enunciados "O forte temporal deixou muito estrago na aldeia mas a casa de palha de sapé não teve dano algum" e "A casa de telha avoou de todos os lados mas a casa de sapé ficou segura" expõem uma memória que prioriza e considera melhores as construções e os espaços em que vivem o homem branco e indica outra posição discursiva (em relação à modernidade e ao progresso) que orienta uma conclusão em favor do modo de viver dos índios, segundo o qual as construções de sapé são seguras e não oferecem riscos. Semelhante contraposição se realiza no enunciado "A casa de sapé é muito gostosa de morar, tem seu ambiente muito fresco" que aponta para uma valoração da casa de sapé não mais como espaço de segurança e sim como espaço de acolhimento e conforto em função de sua estrutura material. Percebe-se como os processos de ocupação do território se articulam às práticas culturais de um grupo e como os seus conflitos identitários se materializam nas territorialidades fragmentadas.

Se delimitarmos a sequência apresentada acima em duas partes, podemos considerar a primeira parte ( da linha 1 à linha 7) como a sequência narrativa na qual o sujeito narra na primeira pessoa do singular a história do temporal e o que aconteceu com suas casas e família e a segunda parte ( da linha 7 à linha 15) como uma sequência exortativa, que, pela própria tipologia de exaltação, inicia-se com a referência ao grupo "então, meu 
povo terena", e assume-se, em seguida a primeira pessoa do plural através do uso do pronome "nós" que aponta para um coletivo cujos limites são necessariamente circunscritos ao grupo Terena. Certamente não é qualquer sujeito indígena que pode repetir esse enunciado. Trata-se de um sujeito indígena cuja profissão - de professor - ocupa um lugar de prestígio e de autoridade nas comunidades indígenas. É importante lembrarmos, em conformidade com Foucault (1986, p. 109), que os enunciados são regrados e que "descrever uma formulação enquanto enunciado não consiste em analisar as relações entre o autor e o que ele disse (ou quis dizer, ou disse sem querer); mas em determinar qual é a posição que pode e deve ocupar todo indivíduo para ser seu sujeito". Portanto, não é o indivíduo, ser empiricamente localizável e suas intenções ao dizer que estão em questão, mas a relação constitutiva entre sujeito e o que ele diz, relação historicamente determinada. Neste fragmento, é para o povo Terena que o sujeito indígena professor enuncia, utilizando como argumento o ensinamento passado, segundo ele, por seus ancestrais: "nós não temos motivos de nós deixarmos a maneira de nós vivermos. Isso nós aprendemos com os nossos entes queridos, os nossos mestres, os nossos avós" e finaliza seu texto com o enunciado: "deixa coisa dos purutuye de lado". Materializa-se discursivamente a disjunção em que os índios Terena encontram-se de um lado e, do outro, o conjunto formado pelos purutuye (homem branco) e põe em evidência a memória discursivizada de que os Terena abandonaram suas raízes e se tornaram índios urbanos. Daí a necessária advertência verbalizada pelo sujeito: "deixa coisa dos purutuye de lado".

Assim, a questão da disputa pela terra que se arrasta desde o século XIX e que provocou transformações fundamentais nas relações com a sociedade envolvente, o confinamento em reservas cuja exiguidade do espaço não permite que este povo dê continuidade às práticas econômicas e culturais de seus ancestrais, a opção por viver em dupla residência - a "casa do branco" e a "casa do índio - nos sugerem que a incerteza na 
definição dos territórios afeta seus processos de territorialização e é parte constitutiva das identidades desses povos. Vargas (2010) chama a atenção para o fato de que esta trajetória de insegurança territorial faz com que a sociabilidade Terena se apresente como um eterno recomeçar. Consequentemente, podemos entender que as territorialidades Terenas apontam para um constante estado de fluxo.

Retomando a compreensão dos processos identitários apresentada por Coracini - a identidade é formada por fragmentos de crenças, valores, ideologias que nos precedem e que recebemos como herança, que podem sofrer modificações e transformações - é possível entrever que os processos de deslocamento e de mudanças territoriais dos povos Terenas, a intervenção governamental nos modos de organização de suas habitações, as formas de circulação pela paisagem urbana e as relações estabelecidas com a comunidade em seu entorno afetam e produzem transformações em suas compreensões do mundo e em suas práticas identitárias que, por sua vez, incidem na produção de territorialidades próprias.

\section{Considerações Finais}

Nas reflexões apresentadas, depreendemos o funcionamento de duas diferentes posições sujeito, constituídas em duas formações discursivas que estão relacionadas entre si por oposição. A primeira formação discursiva em que se pode dizer que os modos de vida do homem branco produzidos pelo desenvolvimento e pelo progresso são melhores que os modos de vida indígena e uma segunda formação discursiva em que se afirmam as práticas culturais e modos de vida indígena. Assim, os processos de identificação configuram uma relação conflituosa, que coloca em jogo a formação discursiva indígena e a formação discursiva não-indígena.

Naquilo que é tomado do nível da constituição (o interdiscurso) para a formulação, deixa-se entrever a memória a que se filiam os sentidos no 
segmento analisado, memória que remete à valorização da cultura tradicional indígena, o que nos permite considerar uma construção identitária heterogênea e em constante transformação.

Nessa análise, pudemos perceber que há uma estreita relação entre os processos de territorialização e as representações presentes no imaginário Terena. A partir dos conflitos históricos vivenciados por estes povos, das suas crenças, das suas práticas culturais, de suas memórias e das imagens estereotipadas presentes em nossa sociedade acerca destes indígenas, as territorialidades são construídas, desconstruídas e reconstruídas.

Estas breves considerações nos apontam para a importância e a necessidade de aprofundar as reflexões sobre o modo como os sujeitos indígenas criam, constroem e reconstroem suas territorialidades a fim de compreendermos melhor seus processos identitários.

\section{Referências}

AZANHA, Gilberto. As terras indígenas Terena no Mato Grosso do Sul. Revista de Estudos e Pesquisas, FUNAI, Brasília, v.2, n.1, p.61-111, jul. 2005

CORACINI, Maria José R. F. (Org.). O desejo da teoria e a contingência da prática: discursos sobre e na sala de aula (língua materna e língua estrangeira). Campinas: Mercado de Letras, 2003.

CORACINI, Maria José R. F. (Org). O jogo discursivo na aula de leitura. Língua materna e lingua estrangeira. Campinas: Pontes, 1995.

COSTA, Adriana Aparecida Vaz da; HONÓRIO, Maria Aparecida. Lugares de identificação do sujeito-índio no discurso do conhecimento: entre lugares. In: CELLI - Colóquio de estudos linguísticos e literários. 3, 2007, Maringá. Anais... Maringá, 2009, p. 1095-1103.

FOUCAULT, Michel. [1969]. A arqueologia do saber. Rio de Janeiro, Forense niversitária, 1987.

GUERRA, Vânia M. L. O indígena de Mato Grosso do Sul: práticas identitárias e culturais. São Carlos: Pedro \& João, 2010, 160 p.

HAESBAERT, Rogério. O mito da desterritorialização: do "fim dos territórios" à multi-territorialidade. Rio de Janeiro: Bertrand Brasil, 2004. 
HALL, Stuart. A identidade cultural na pós-modernidade. Trad. de Tomaz Tadeu da Silva e Guacira Lopes Louro. Rio de Janeiro: DP\&A, 2006.

PECHEUX, Michel. Semântica e discurso: uma crítica à afirmação do óbvio. 4. ed. Campinas: Pontes, 2009.

RAJAGOPALAN, Kanavillil. O conceito de identidade em linguística: é chegada a hora para uma reconsideração radical? In: SIGNORINI, I. (Org.). Linguagem e identidade. Campinas: Mercado de Letras, 1998. p.21-45.

VARGAS. Icléia Albuquerque. Territorialidade e representação dos Terenas da Terra Indígena Buriti (MS) - possibilidades didáticos pedagógicos. In: SERPA, A. (Org.). Espaços culturais: vivências, imigrações e representações. Salvador: EDUFBA, 2008

VARGAS, Vera Lúcia. A dimensão sociopolítica do território para os Terena: as aldeias no século XX e XXI. RJ: UFF, 2010. (tese de doutoramento)

\footnotetext{
i E-mail da autora: naircristina.medeiros@gmail.com

ii E-mail da autora: claudetecameschi@gmail.com
} 